\title{
ESPECIFICIDADES DE GÊNERO NO SISTEMA PRISIONAL: dilemas de uma prisão de mulheres.
}

\author{
Laura Monteiro Lubanco \\ Universidade Estadual do Norte Fluminense Darcy Ribeiro (UENF) \\ Email: lauralubanco@hotmail.com
}

\begin{abstract}
RESUMO
$\mathrm{O}$ artigo debate as particularidades de gênero no sistema prisional brasileiro e busca verificar se a condição de mulher apresenta maior vulnerabilidade no cárcere. É realizado um breve apanhado acerca do sistema prisional, são identificadas especificidades de gênero na prisão e a perspectiva macro do encarceramento feminino é contextualizada a partir da análise do Presídio Nilza da Silva Santos. É feito um levantamento bibliográfico sobre o tema e técnicas qualitativas como estudo de casos e observação direta são aplicadas. Constata-se a vulnerabilidade da mulher no sistema prisional derivada da inobservância das peculiaridades femininas.
\end{abstract}

Palavras-chave: Especificidades de Gênero; Sistema Prisional; Vulnerabilidade.

SPECIFICITIES OF GENDER IN PRISON SYSTEM: dilemmas of a women's prison.

\section{ABSTRACT}

The article discusses the gender peculiarities in the Brazilian prison system and seeks to verify if the condition of women presents greater vulnerability in the prison. A brief survey of the prison system is carried out, gender specificities are identified in prison, and the macro perspective of female incarceration is contextualized from the analysis of the Nilza da Silva Santos Prison. A bibliographic survey about the subject is made and qualitative techniques such as case studies and direct observation are applied. The vulnerability of women in the prison system due to nonobservance of women's peculiarities is noted.

Keywords: Gender Specificities; Prison System; Vulnerability. 


\section{INTRODUÇÃO}

De acordo com o último Levantamento Nacional de Informações Penitenciárias (INFOPEN2014), o Brasil possui a quinta maior população carcerária mundial, contando com 607.731 pessoas privadas de liberdade.

Desconsiderado as informações apresentadas pelo relatório do Departamento Penitenciário Nacional (DEPEN) em relação às pessoas custodiadas em carceragens de delegacias ou estabelecimentos similares administrados pelas Secretarias de Segurança Pública, estimadas em 27.950, o país conta com uma população de 579.7811 pessoas custodiadas no Sistema Penitenciário, sendo 37.380 mulheres e 542.401 homens (INFOPEN2014).

No entanto, no período de 2000 a 2014 o aumento da população de mulheres presas foi de $567,4 \%$, em comparação ao crescimento $220,20 \%$ da população prisional masculina, demonstrando, assim, a curva progressiva do encarceramento feminino.

Em que pese a expressiva participação de homens no contingente total de pessoas privadas de liberdade no país, é possível afirmar que a população absoluta de mulheres encarceradas no sistema penitenciário cresceu $567 \%$ entre os anos 2000 e 2014, chegando ao patamar de 37.380 mulheres. Já a população de homens encarcerados cresceu $220 \%$ no mesmo período, seguindo a tendência geral de aumento do encarceramento no Brasil. Se em 2000 as mulheres representavam 3,2\% da população prisional, em 2014 elas passaram a representar 6,4\% do total encarcerado. (INFOPEN 2014: 10)

O encarceramento de mulheres tem se mostrado progressivo. No que tange ao crescimento da população carcerária feminino no sistema penitenciário, é possível identificar uma dinâmica cada vez mais contundente de encarceramento em massa, contudo, ainda há uma carência de informações oficiais no que se refere à condição do aprisionamento feminino, contribuindo para a invisibilidade das mulheres privadas de liberdade. Tal invisibilidade demonstra e reforça os sinais da desigualdade de gênero que permeiam a sociedade brasileira.

Nesse ínterim, o presente artigo deriva de uma pesquisa que tem como tema central a desigualdade de gênero no âmbito do sistema prisional e apresenta como objeto a vulnerabilidade feminina no cárcere. Tal estudo justifica-se pela imprescindibilidade em dar visibilidade às mulheres inseridas no sistema prisional

Ao problematizar as especificidades de gênero no contexto da prisão, sob uma ótica interdisciplinar que engloba a sociológica e o direito, busco verificar se há vulnerabilidade intramuros ao que concerne a ser uma mulher dentro de um estabelecimento penal. Assim, o estudo tem como objetivo central identificar vulnerabilidades advindas da condição de gênero no âmbito da privação de liberdade. 
A fim de cumprir o objetivo geral elencado, o artigo é integrado substancialmente por objetivos específicos que conduzem sua estrutura e buscam, essencialmente, nortear todo o estudo. Destarte, constituem-se como objetivos específicos: realizar um breve apanhado acerca do sistema prisional brasileiro; compreender o cenário da mulher no cárcere; identificar as especificidades de gênero inseridas no sistema prisional brasileiro; e contextualizar a perspectiva macro do encarceramento feminino sob uma ótica micro a partir da análise, a nível local, do Presídio Nilza da Silva Santos.

No intuito de atingir o propósito estabelecido e alcançar de maneira efetiva as finalidades propostas, optou-se por empregar técnicas qualitativas de investigação, haja vista que a partir de tal enfoque a preocupação do pesquisador não é com a representatividade numérica do grupo pesquisado, mas sim com o aprofundamento necessário à compreensão do fenômeno.

Para coletar os dados necessários ao estudo utilizou-se como método o estudo de caso, já que tal método possibilita a utilização de uma diversidade de fontes de evidências para um exame profundo e intenso sobre o fenômeno investigado.

Conforme aponta Mírian Goldenberg (2011), o estudo de caso não é uma técnica específica, mas uma análise holística, a mais completa possível. O estudo de caso reúne o maior número de informações detalhadas, por meio de diferentes técnicas de pesquisa, com o objetivo de apreender a totalidade de uma situação e descrever a complexidade de um caso concreto. Através de um mergulho profundo e exaustivo em um objeto delimitado, o estudo de caso possibilita a penetração na realidade social, não conseguida pela análise estatística.

Assim, foi inicialmente realizada uma intensa pesquisa bibliográfica a partir do levantamento de referências teóricas publicadas por meios escritos e eletrônicos, como livros, artigos científicos, dissertações e teses que tratam sobre o tema em questão, o que permitiu a pesquisadora compreender melhor o objeto em análise.

Em seguida, foi aplicada a técnica da observação direta, realizada dentro do sistema prisional feminino do município de Campos dos Goytacazes, o Presídio Nilza da Silva Santos, que possibilitou reunir uma extensa gama de evidências ao que concerne às especificidades de gênero no cárcere a nível local.

Por fim, foram realizadas entrevistas com informantes chaves que compõem o quadro de sujeitos da pesquisa, como membros da pastoral carcerária de campos que atuam no presídio Nilza da Silva Santos, funcionários da referida unidade prisional e mulheres que se encontram privadas de liberdade no referido estabelecimento penal. 
Desse modo, foi possível contextualizar a perspectiva macro do objeto em estudo a partir da análise a nível local e vislumbrar as questões concatenadas à vulnerabilidade de gênero no âmbito no sistema prisional.

\title{
1. BREVE APANHADO ACERCA DO SISTEMA PRISIONAL BRASILEIRO
}

O sistema prisional brasileiro é marcado por um estado contínuo de precariedade, sendo certo que nunca operou de maneira satisfatória. Há 376.669 vagas no sistema prisional para atender os 607.731 presos, ou seja, há um déficit de 231.062 vagas (INFOPEN 2014).

Sob a ótica de Sérgio Adorno (1991), fatores como a superlotação dos presídios, as condições sanitárias rudimentares, a alimentação deteriorada, a deficiente assistência médica, jurídica, social, educacional e profissional indicam a fragilidade dos estabelecimentos penais no Brasil.

A segunda edição do relatório Visão do Ministério Público sobre o Sistema Prisional Brasileiro (2016), que agrega os dados colhidos por Promotores de Justiça e Procuradores da República em 2014 e 2015, por ocasião das regulares inspeções carcerárias, reforça as graves deficiências estruturais do sistema prisional brasileiro, como a superlotação carcerária e as condições desumanas de custódia, ocasionado grave violação de direitos fundamentais.

A partir do trabalho realizado pelo Conselho Nacional do Ministério Público no sistema prisional brasileiro, foram constatadas também diversas violações dos direitos humanos, como:

\begin{abstract}
celas superlotadas (de até 300\%), fétidas e úmidas; presos provisórios e definitivos dividindo as mesmas celas; presos devedores de alimentos recolhidos junto aos presos comuns; internas gestantes e puérperas com suas crianças dividindo celas superlotadas com presas comuns; ausência de banho de sol e visitas nos casos de presos em delegacias de polícia; ausência de fornecimento de material básico de higiene pessoal e uniformes; ausência de banco de dados dos presos; precário sistema de escolta e transporte de presos, com constante adiamento das audiências designadas pelos Juízos criminais; ausência ou irregularidades quanto ao acesso à saúde por parte dos presos; irregularidades com relação à Unidade de Psiquiatria e Custódia; alimentação imprópria para o consumo humano; número de agentes penitenciários em desconformidade com o preconizado pela ONU (MINISTÉRIO PÚBLICO 2016: 28).
\end{abstract}

De acordo com o relatório, a superlotação é agravada devido à quantidade exorbitante de indivíduos que aguardam presos ao julgamento. No Brasil, aproximadamente $40 \%$ do total de internos estão presos provisoriamente, na medida em que a média mundial se encontra em torno de $25 \%$.

Conforme a segunda edição do relatório Visão do Ministério Público sobre o Sistema Prisional Brasileiro (2016), é recorrente a fixação de convênios entre a União e Estados com o 
intuito de gerar melhorias no sistema prisional, todavia, a execução dos projetos, muitas vezes sem fundamentação, não é consolidada. Para o Ministério Público (2016), a inércia no tocante a investimentos e melhorias nos estabelecimentos penais caracteriza, inclusive, atos de improbidade administrativa.

É inevitável inferir que a negligência com que o sistema prisional é tratado demonstra, de fato, a escassez de interesse político na matéria. O investimento no setor prisional é muitas vezes visto de forma negativa sob a ótica política, já que empregar recursos em tal segmento não apenas não atrai eleitores como também não é visto com bons olhos pelos sufragistas. A atuação política em relação ao sistema prisional é também reflexo do desinteresse da população pelo tema.

O descaso com o sistema prisional reduz a perspectiva de reintegração social positiva do indivíduo preso e consequentemente restringe a possibilidade de prevenção de novos delitos. Os direitos básicos de quem se encontra cumprindo pena privativa de liberdade no Brasil ou em situação de prisão provisória não são em momento algum respeitados. Não há condições legais para a devida consumação da pena de acordo com o regime determinado; não é realizada a separação e classificação dos internos conforme critérios previamente estabelecidos; tampouco, o regime disciplinar é implementado de acordo com as normas, gerando uma situação de injustiça durante todo o período de reclusão.

Convém salientar que o sistema punitivo atual é tido como método mais sutil de punição ao substituir os castigos corporais explícitos. Sob a ótica de Michael Foucault (1999), o encarceramento é a decorrência de uma lógica burguesa em que a privação de liberdade faz parte de um desenvolvimento do mecanismo da sanção como resultado de um Estado Liberal. Dessa maneira, a prisão caracteriza-se como meio de execução do poder e como um dispositivo capaz de controlar, administrar e preservar o espaço social. Através da anulação das vontades e dos desejos pessoais do condenado, busca o adestramento social daqueles que praticaram uma conduta desviante.

Erving Goffman (1974) vai além e aproxima as instituições prisionais, o poder disciplinar e a ideia de reinserção do indivíduo às singularidades do “eu”. Em sua obra Manicômios Prisões e Conventos, o autor (GOFFMAN 1974) busca explorar as características gerais das instituições totais e identificar o mundo vivenciado e percepcionado pelos nelas internados, esbarrando assim em suas subjetividades.

Goffman (1974) atribui às prisões a qualidade de instituições totais, definidas como "um local de residência e trabalho onde um grande número de indivíduos com situação semelhante, 
separados da sociedade mais ampla por considerável período de tempo, levam uma vida fechada e formalmente administrada" (GOFFMAN 1974: 6).

A totalidade atribuída às instituições disciplinares por Goffman (1974) configura-se em seu fechamento através das barreiras físicas estabelecidas e da arquitetura da construção, que dividem o mundo externo e o mundo da instituição e dificultam o contato com o exterior. O limite e a interrupção do contato com o mundo externo determinados pela estrutura física da instituição dão início ao processo de mortificação do self a partir da perda do papel social previamente representado.

Como vemos, a violência incorpórea estabelecida pela pena de prisão suspende direitos individuais e promove a mortificação do eu ao passo que adéqua o condenado ao padrão da organização institucional, ignorando todas as suas vontades e particularidades.

Contudo, a desproporcionalidade do castigo nas prisões brasileiras devido à inobservância das normas que deveriam garantir a manutenção de direitos básicos à dignidade da pessoa humana intensifica todo o processo de mortificação do self, já inerentes à instituição prisional.

Neste ínterim, as disfunções do sistema prisional não são distintas em razão do sexo. As mulheres encarceradas passam por problemas semelhantes aos homens em situação de reclusão ao que condiz aos problemas referentes à situação nefasta em que se encontram os estabelecimentos penais voltados à execução da pena privativa de liberdade. No entanto, a situação da mulher presa é ainda mais vulnerável em razão da inobservância das especificidades de gênero que carece a população feminina privada de liberdade.

\section{ESPECIFICIDADES DE GÊNERO INTRAMUROS: O CENÁRIO DA MULHER NO CÁRCERE}

As relações estabelecidas pelas mulheres privadas de liberdade, tanto no âmbito da família como também ao que concerne ao envolvimento com o crime, anunciam-se, em geral, de forma muito heterogênea quando equiparadas com a realidade da população masculina encarcerada.

Há um padrão muito específico referente ao perfil da população feminina que ocupa as prisões brasileiras

Segundo os dados do INFOPEN Mulheres (2015), a população carcerária feminina é composta por jovens, com filhos, encarregadas pelo sustento familiar, possuidoras de um baixo nível de escolarização, provenientes de extratos sociais economicamente carentes. Em torno de $68 \%$ delas têm a prisão ligada ao tráfico de drogas, no entanto, o vínculo não está relacionado às grandes 
redes do crime organizado, não exercendo uma função de grande importância para o delito, atuando de modo coadjuvante no crime.

De acordo com o Relatório Sobre Mulheres Encarceradas no Brasil (2007), realizado pela Pastoral Carcerária, há uma histórica omissão dos poderes públicos quando se trata de encarceramento feminino, evidenciada pela ausência de políticas públicas que contemplem a mulher encarcerada como sujeito de direitos considerando as suas especificidades advindas das questões de gênero.

Ao observarmos as informações referentes à população prisional, verificamos uma disparidade relativa à quantidade de dados referentes à população feminina quando comparada à população masculina. "Se analisarmos a série histórica de 2000 a 2014, é possível identificar a ausência de dados desagregados por gênero para as pessoas custodiadas nas delegacias e carceragens nos anos de 2003 e 2014”. (INFOPEN 2015: 7)

De acordo com Mariana Barcinski e Sabrina Daiana Cúnico (2014), “os estudos tradicionais com perspectivas teóricas e socio-históricas da instituição prisional, tais como os de Michel Foucault (1999) e Erving Goffman (1974), apresentam a experiência do cárcere a partir da vivência das prisões masculinas" (BARCINSKI E CÚNICO 2014: 2), ou seja, partem de uma ótica masculina da instituição prisional.

Consoante aos dados do INFOPEN Mulheres (2015), historicamente, a ótica masculina tem se potencializado no contexto prisional, com reprodução de serviços penais direcionados para homens, deixando em segundo plano as diversidades que compõem o universo das mulheres, que se relacionam com sua raça e etnia, idade, deficiência, orientação sexual, identidade de gênero, nacionalidade, situação de gestação e maternidade, entre tantas outras nuances.

Conforme ressalta Magali Oliveira e André Santos (2012), a supressão de direitos dos presos é recorrente, no entanto, tende a ser em maior intensidade quando se trata da população carcerária feminina, na medida em que os direitos advindos da condição de gênero não são considerados.

Necessário salientar que não há o que se falar em discriminação em relação ao homem ao solicitar dissonância no tratamento em razão do gênero. Conforme estabelece o Conjunto de Princípios para a Proteção de Todas as Pessoas Sujeitas a Qualquer forma de Detenção ou Prisão elaborado pela Organização das Nações Unidas (ONU 1988).

As medidas aplicadas ao abrigo da lei e exclusivamente destinadas a proteger os direitos e a condição especial da mulher, especialmente da mulher grávida e da mãe com crianças de tenra idade, das crianças, dos adolescentes e idosos, doentes ou deficientes não são consideradas medidas discriminatórias (ONU 1988). 
Para Heidi Ann Cerneka (2009), “o sistema penal no Brasil e no mundo foi criado por homens e para homens" (CERNEKA 2009). E o fato de o número de mulheres presas ainda ser relativamente pequeno, em comparação à população carcerária masculina, faz com que suas necessidades muitas vezes passem despercebidas ou simplesmente sejam desconsideradas.

Segundo a autora (CERNEKA 2009), o mundo inteiro adaptou prédios a fim de alojar a população carcerária feminina, deste modo, é raro encontrar presídios femininos que tenham sido de fato construídos para este fim.

Convém ressaltar que há instalações em que nem as pequenas adequações foram realizadas, e as mulheres privadas de liberdade recebem exatamente o mesmo tratamento que a população masculina.

As demandas da população prisional feminina tendem a ser altamente específicas e a inobservância às nuances que compõem o universo feminino é ainda mais acentuada dentro das prisões desenvolvidas essencialmente por homens e para homens. Há um descaso intensificado nas estruturas arquitetônicas e equipamentos internos das instituições fechadas destinadas à população feminina.

Os dados levantados pelo INFOPEN (2014) demonstram que há 1.070 unidades de estabelecimentos penais masculinas, o que configura um percentual de 75\%, 238 estabelecimentos mistos (17\%) e 103 estabelecimentos femininos (7\%), significando, assim, que a maior parte das mulheres está inserida em estruturas mistas, o que vai de encontro ao que é estabelecido pela Lei de Execução Penal (lei no 7.210 de 11 de julho de 1984).

A divisão de estabelecimentos prisionais em masculinos e femininos é um dever estatal, previsto pela Lei de Execução Penal (lei no 7.210, de 11 de julho de 1984). O desígnio dos espaços de acordo com o gênero constitui elemento primordial para a implementação de políticas públicas específicas às necessidades da mulher encarcerada.

Uma necessidade muito específica das mulheres na prisão é a questão da saúde e, principalmente, a saúde reprodutiva. $\mathrm{Na}$ faixa etária mais comum da população prisional feminina, não é raro lidar com gravidez, doenças sexualmente transmissíveis, depressão e outros transtornos mentais (CERNEKA 2009: 72)

É irrefutável a afirmação de que um dos mais críticos problemas dos estabelecimentos penais brasileiras é inerente a sua própria estrutura física. Dentre outras tantas mazelas comuns aos cárceres, como celas superlotadas, péssimas condições de arejamento, luminosidade e salubridade, 
ao que compete à estrutura física de um espaço reservado a mulheres, dados referentes a um ambiente que torne a maternidade minimamente exequível devem ser considerados.

O levantamento realizado pelo INFOPEN (2015) traz dados que contemplam a questão da maternidade no ambiente carcerário, realizando uma análise ao que tange a existência de celas específicas para gestantes, berçários, creches e centros de referência materno-infantil.

Conforme o INFOPEN (2015), no que toca à infraestrutura das unidades que custodiam mulheres, apenas 34\% dos estabelecimentos femininos possuem cela ou dormitório adequado para gestantes, enquanto nos estabelecimentos mistos, apenas 6\% das unidades detêm espaço apropriado à custódia de gestantes.

Vale frisar que as mulheres que dão à luz no sistema prisional não possuem nenhum direito de escolha em relação ao nascimento do bebê. Entrou em vigor no dia 13 de abril de 2017 a Lei ${ }^{\circ}$ 13.434, que proíbe que a mulher seja algemada durante o parto, conquanto seja pouco crível a necessidade de uma norma legal para impedir que uma mulher seja algemada durante o momento de dar à luz. Sabe-se que a utilização de algemas deve se restringir a casos excepcionais, havendo, efetivamente, perigo de fuga ou resistência por parte do preso.

Conforme a Súmula Vinculante 11 do Supremo Tribunal Federal (2008)

Só é lícito o uso de algemas em casos de resistência e de fundado receio de fuga ou de perigo à integridade física própria ou alheia, por parte do preso ou de terceiros, justificada a excepcionalidade por escrito, sob pena de responsabilidade disciplinar, civil e penal do agente ou da autoridade e de nulidade da prisão ou do ato processual a que se refere, sem prejuízo da responsabilidade civil do Estado.

No entanto, o estado de São Paulo, em 2011, submeteu uma detenta a cruel, desumana e degradante manutenção de algemas nós pés e nas mãos durante seu trabalho de parto.

A mulher no período gestacional encontra-se em uma condição excêntrica, detém necessidades singulares e deve receber condições especiais de tratamento, contrárias ao que tem se realizado até então. A determinação por um tratamento diferenciado às mulheres nessa situação específica provém, assim, da própria condição inerente à gestação, devendo ser respeitado em qualquer espaço, público ou privado, bem como no cárcere, local em que o indivíduo se encontra sob total tutela estatal.

Assim como cuidados no período gestacional são fundamentais para garantir à saúde da mulher e do feto, o período de aleitamento materno é primordial para a nutrição e o bom desenvolvimento da criança. No entanto, as estruturas carcerárias destinadas a tais fins, quando presentes, são, na maior parte das vezes, improvisadas. 
Ao que se refere à existência de berçário ou centro de referência materno infantil, $32 \%$ das unidades femininas dispunham do espaço, enquanto apenas $3 \%$ das unidades mistas o contemplavam. Já em relação à implantação de creches, apenas 5\% das unidades prisionais femininas dispunham desse direito, não sendo registrada nenhuma creche instalada em unidades mistas.

Reforço, novamente, o fato da maioria dessas unidades ter sido desenvolvida para receber a população carcerária masculina e posteriormente transformada em unidades prisionais designadas a mulheres, motivando assim a inexistência de espaço apropriado para a amamentação, berçário e creche, estrutura minimamente necessária para acolher mães de crianças que já nascem sob a custódia do Estado. Conclui-se que a grande maioria dos presídios não está apta a atender tais especificidades.

Não o bastante, há também um desamparo de caráter social, que pune moralmente a mulher considerada transgressora.

Para Goffman (1988), um atributo que torna o indivíduo menos desejável em uma relação social é definido como um Estigma. A passagem pela prisão por si só, constituída por todos os seus estereótipos, é uma condição que engendra descrédito nas relações sociais, tornado o indivíduo menos desejável, sendo assim uma característica estigmatizante.

No caso da população prisional feminina esse efeito estigmatizante é ainda mais acentuado à medida que a mulher, além de carregar o atributo negativo advindo da passagem pelo cárcere, se desvia dos papeis sociais que se espera dela ou, ainda, representa papeis que, aos olhos da sociedade em que está inserida, são contraditórios, sendo duplamente punida.

Uma mulher que vem a ser presa e carrega o estigma de presidiária tende a ser duplamente punida, pois além da pena decorrendo da mão forte do Estado, recai sobre ela a reprovação social que não espera de uma mulher comportamentos tidos como desviantes.

Conforme traz o relatório do Ministério Público (2016), há um nítido contraste entre as unidades prisionais que abrigam condenados do sexo masculino, em que a grande maioria dos internos recebe assistência e visitas de familiares, e as unidades de presídios femininos, onde a quantidade de pessoas nas filas de visitas demonstra que um reduzido número de internas possui visitantes assíduos. "São raros os casos em que cônjuges buscam manter contato com mulheres presas, pois muitas delas acabam sendo esquecidas, negligenciadas até mesmo pelas próprias famílias" (MINISTÉRIO PÚBLICO 2016: 33)

Consoante Luciana Boiteuxet al. (2014), ao delinquir, a mulher rompe não só com a lei penal, mas também com as normas sociais e com o seu papel cultural e social pré-estabelecidos e, 
neste ínterim, viola a norma duplamente, razão pela qual é duplamente punida quando adentra as esferas formais de controle.

Quando presa, a mulher experimenta maior discriminação por parte da sociedade e maior abandono por parte da família, como fica evidenciado pelas pequenas filas de visitas em presídios femininos, ao contrário das filas dos presídios masculinos, com mulheres e crianças cheias de sacolas de comida, roupas e produtos de higiene. As mulheres, nas filas, estão cumprindo seu papel de mulher, esposa, mãe, enquanto as presas que ousaram desafiar as leis do país e da família estão sujeitas a rígidas medidas de observação, vigilância e controle.

É preciso destacar que a ruptura dos laços familiares ocasionada devido à prisão da mulher suprime, muitas vezes, a relação com os filhos, que ficam sobre cuidados de parentes, do Estado, ou, em alguns casos, desamparados e mais propensos à criminalidade.

Para Cerneka (2009):

não se pode considerar isoladamente a mulher infratora no momento da sentença ou no momento de manter a prisão preventiva, pois ela é parte de um sistema familiar e as consequências desta decisão judicial recaem duramente sobre seus filhos e suas famílias. Os efeitos colaterais são tão significativos que têm de ser considerados na sentença - na individualização da pena que está garantida por lei. (CERNEKA, 2009, p.70)

Para Barcinski e Cúnico (2014), como ser primordialmente relacional, a mulher experimenta a separação e o abandono impostos pelo encarceramento como uma ameaça a sua própria identidade. A suspensão ou perda do papel desempenhado extramuros altera sobremaneira a subjetividade da mulher.

No que concerne à mortificação do self inerente ao cárcere, a mulher, mais uma vez, está em situação de desvantagem. Para Elaine Cristina Pimentel Costa (2011), a constituição da identidade feminina está, de fato, diretamente ligada às formas pelas quais as representações sociais sobre as mulheres se constroem ao longo da história, ordenando a vida social. O encarceramento suspende muitos dos papeis desempenhados pela mulher, ao menos, durante o período de reclusão, engendrando em profunda degradação identitária, que reflete sobremaneira em sua situação pós cárcere.

\section{CONTEXTO LOCAL: O PRESÍDIO NILZA DA SILVA SANTOS}

Aproximando as questões elencadas à realidade do Presídio Nilza da Silva Santos, verificase a reprodução de tal cenário a nível local. 
O Presídio Nilza da Silva Santos, situado do município de Campos dos Goytacazes/RJ, é hoje destinado à população carcerária feminina que se encontra presa provisoriamente ou cumprindo pena privativa de liberdade. No entanto, como a grande maioria dos presídios femininos espalhados pelo país, inicialmente era destinado à custódia da população masculina de presos da região, onde funcionava o Presídio Carlos Tinoco da Fonseca.

Assim como os tantos presídios criados para homens e por homens (CERNEKA 2009), o Presídio Nilza da Silva Santos foi adaptado para receber mulheres. Contudo, as adaptações foram extremamente insignificantes e não suprem as necessidades advindas das especificidades de gênero. O artigo 41, inciso XII, da Lei 7.210 de 1984 estabelece igualdade de tratamento, salvo quanto às exigências da individualização da pena. No mesmo sentido o artigo 82 dispõe que a mulher deverá ser recolhida a estabelecimento próprio e adequado a sua condição pessoal. Porém, a individualização da pena e as especificidades de gênero não são consideradas e as mulheres são tratadas como homens, no entanto, menstruam uma vez ao mês (CERNEKA 2009).

Para Leni Colares e Luiz Chies (2010) apesar do aumento significativo da população carcerária de mulheres, o improviso da instituição não se dá através do emprego de mudanças que possibilitem, de fato, satisfazer as particularidades dessa população, mas sim no encarceramento em ambientes que não consistem em nada mais que partes dos estabelecimentos masculinos, onde essas mulheres passam a ocupar celas ou alas denominadas como 'femininas'.

Para Barcinski e Cúnico (2014), o improviso institucional que marca a situação da mulher no cárcere, a qual é tratada a partir de tentativas de adaptações do sistema já existente, reflete o caráter androcêntrico do sistema prisional.

Dessa forma, o processo de mortificação do self dentro do estabelecimento penal, não só no presídio Nilza da Silva como em diversas outras penitenciárias, tende a ser mais intenso quando se trata da população feminina. Além do processo de perda da subjetividade inerente ao cárcere, no caso das mulheres, muitas vezes as formas de expressão da feminilidade são vedadas.

$\mathrm{Na}$ penitenciária feminina situada no município de Campos dos Goytacazes, o caráter androcêntrico do sistema pode ser evidenciado na distribuição de uniformes masculinos às mulheres reclusas. As vestes distribuídas às presas são as mesmas que são distribuídas à população carcerária masculina. A padronização desconsidera o gênero. A entrada de maquiagem é restrita e espelhos não são permitidos.

Podemos identificar, assim, a supressão do que Goffman (1974) chama de "estojo de identidade", traduzindo-se no conjunto de elementos, serviços e instrumentos capazes de permitir a 
manipulação da apresentação pessoal. A expressão da feminilidade e da sua apresentação pessoal como mulher é restrita, engendrando em maior deterioração da identidade.

Não o bastante, conforme acentual Barcinski e Cúnico (2014), o fato de a prisão em si ser masculina e masculinizante em grande parte de suas práticas torna as mulheres presas ainda mais invisíveis. A invisibilidade da mulher no cárcere se traduz em ausência de políticas públicas e supressão de elementos básicos à preservação de seus direitos individuais e à manutenção de sua dignidade enquanto ser humano.

Convém ressaltar que a unidade não possui elementos básicos capazes de assistir a mulher gestante ou em período de amamentação, quiçá abrigar seus filhos, apesar da Lei de Execuções Penais estabelecer que a penitenciária de mulheres deve ser dotada de berçário, onde as condenadas possam cuidar de seus filhos, inclusive amamentá-los, no mínimo, até 6 (seis) meses de idade, seção para gestante e parturiente, além de creche para abrigar crianças maiores de 6 (seis) meses e menores de 7 (sete) anos, com a finalidade de assistir a criança desamparada cuja responsável estiver presa.

Não há maternidade, espaço para aleitamento, creche ou qualquer outro ambiente voltado à manutenção do bebê e da criança desamparada. Não o bastante, não há disponibilização de médicos aptos a realizarem o acompanhamento necessário à mulher durante o pré-natal e o período pósparto, contrariando o que é elencado pela Lei 7.210 de 1984, que assegura o acompanhamento médico à mulher, principalmente no pré-natal e no pós parto, sendo extensivo ao recém-nascido.

Em caso de gestação, a detenta é encaminhada à Unidade Materno Infantil (UMI), na Penitenciária Talavera Bruce, em Bangu, no Rio de Janeiro, dificultando ainda mais o contato com a família e intensificando o processo de segregação e a ruptura de laços devido à distância e à falta de recursos financeiros para comparecer às visitas.

Outra violação que vai de encontro às normas elencadas na Lei de Execução Penal também está ligada à estrutura e à capacidade física do estabelecimento. $\mathrm{O}$ artigo 85 da referida norma determina que o estabelecimento penal tenha lotação compatível com a sua estrutura e finalidade, contudo, assim como a maioria dos espaços destinados à execução da pena privativa de liberdade no país, a lotação está acima da capacidade máxima permitida, contabilizando um total de 359 mulheres presas em um espaço que suporta 224 detentas. Ou seja, há um déficit de 135 vagas, o que corresponde a uma superlotação de $60 \%$ acima do limite permitido.

Ademais, os condenados deveriam permanecer alojados em celas individuais que disponha de dormitório, aparelho sanitário e lavatório (Lei 7.210 de 1984), todavia há em média 20 detentas alojadas em cada cela. 
Diversas outras violações ao que determina a Lei de Execuções Penais, sobremaneira ao que concerne às especificidades de gênero, também podem ser identificadas na unidade prisional Nilza da Silva Santos.

O artigo 19 da norma (Lei 7.210 de 1984) determinada que o ensino profissional seja ministrado em nível de iniciação ou de aperfeiçoamento técnico e designa, em seu inciso primeiro, que a mulher condenada tenha ensino profissional adequado à sua condição. Contudo, a implementação de projetos voltados à profissionalização na unidade feminina de Campos é precária e não atende à norma. No momento, não há curso profissionalizante disponível no para as reclusas, o que impede a possibilidade de uma melhor reintegração ao meio social advindo da capacitação profissional.

Fica claro que a inobservância das normas que buscam reduzir as desigualdades de gênero no sistema prisional é reproduzida no presídio Nilza da Silva Santos, a partir do momento em que as medidas específicas e imprescindíveis a uma prisão de mulheres não são adotadas.

\section{CONSIDERAÇÕES FINAIS:}

Verifica-se a partir do presente estudo, que a invisibilidade ao que concerne à prisão de mulheres se manifesta não apenas no âmbito acadêmico como também na esfera estatal, evidenciada pela ausência de políticas públicas voltadas a essa população.

Além da precariedade das informações referentes às mulheres privadas de liberdade, resultante em inação estatal voltada a esse público, as desigualdades de gênero também podem ser observadas no interior do sistema prisional e consolidam-se como mais uma das graves disfunções intramuros.

O tratamento dado à mulher encarcerada não atende às particularidades de gênero, que vão muito além da sua condição de genitora e lactante, e o que se nota é um esforço para adaptar ou adequar a presa a um ambiente que não contempla suas necessidades.

A degradação da identidade da população feminina que passa pelo cárcere é estabelecida tanto pela mortificação do self inerente à pena privativa de liberdade quanto pelas particularidades da sua condição de mulher dentro do sistema prisional.

As dissonâncias do sistema prisional feminino em relação aos dispositivos legais estabelecidos são constatadas a nível local e o contexto macro do encarceramento de mulheres é reproduzido e pode ser exemplificado a partir da observação do Presídio Nilza da Silva Santos, assim como a vulnerabilidade de gênero no interior das penitenciárias advindos da invisibilidade em 
relação à mulher presa e a consequente falta de políticas públicas voltadas a essa população. As adversidades e inobservâncias legais que deveriam ser tidas como exceções são tratadas como regras dentro da realidade prisional da mulher.

Conclui-se que as especificidades entre homens e mulheres devem ser consideradas da aplicação da pena às possibilidades de reintegração social da pessoa presa e egressa, bem como às medidas voltadas ao restabelecimento dos laços sociais e afetivos após a prisão, sobremaneira ao que concerne à superação da estigmatização feminina e à sua múltipla punição.

\section{REFERENNCIAS:}

ADORNO, Sérgio. 1990. Sistema Penitenciário Brasileiro: problemas e desafios. Seminário Justiça e Segurança, Recife.

BARCINSKI, Mariana; CUNICO, Sabrina. 2014. Os efeitos (in)visibilizadores do cárcere: as contradições do sistema prisional. Revista da Associação Portuguesa de Psicologia, v. 28, p. 6370 .

BOITEUX, Luciana. et al. 2009. Tráfico de Drogas e Constituição. Brasília: Ministério da Justiça. Série Pensando o Direito, v. 1.

BRASIL. Lei n 7.210, de 11 de julho. 1984. Texto compilado Institui a Lei de Execução Penal.

BRASIL. Supremo Tribunal Federal. Súmula nº 11, 2008.

BRASIL. Ministério da Justiça. Levantamento Nacional de Informações Penitenciárias INFOPEN Junho de 2014. Departamento Penitenciário Nacional - DEPEN, 2014

BRASIL. Ministério da Justiça. Departamento Penitenciário Nacional. Levantamento Nacional de informações penitenciárias. INFOPEN mulheres - Junho de 2014. Brasília: INFOPEN, 2015.

BRASIL. Conselho Nacional do Ministério Público. A Visão do Ministério Público sobre o Sistema Prisional Brasileiro. 2016

BRASIL. Lei $\mathbf{n}^{0} \mathbf{1 3 . 4 3 4}$ de 13 de abril de 2017.

CERNEKA, Heidi Ann. 2009. Homens que menstruam: considerações acerca do sistema prisional às especificidades da mulher. Belo Horizonte: Veredas do Direito.

COLLARES, Leni; CHIES, Luiz. 2010. Mulheres nas so(m)bras: invisibilidade, reciclagem e dominação viril em presídios masculinamente mistos. Revista Estudos Feministas vol. 18. p. 407 424.

COSTA, Elaine. 2011. Enfim a Liberdade: as mulheres e a vivência pós-cárcere. Tese Universidade Federal de Pernambuco. 
FOUCAULT, Michel. 1999. Vigiar e Punir: História da violência nas prisões. 20. ed. Rio de Janeiro: Vozes. Tradução Raquel Ramalhete.

GOFFMAN, Erving. 1974. Manicômios, prisões e conventos. São Paulo. Editora Perspectiva.

GOFFMAN, Erving. 1988. Estigma: Notas sobre a Manipulação da Identidade Deteriorada. Rio de Janeiro: Guanabara Koogan.

GOLDENBERG, Mirian. 2011. A arte de pesquisar: como fazer pesquisa qualitativa em Ciências Sociais. 12 Edição. Editora Record.

OLIVEIRA, Magali; SANTOS, André. 2012. Desigualdade de Gênero no Sistema Prisional: considerações acerca das barreiras à realização de visitas e visitas íntimas às mulheres encarceradas. Caderno Espaço Feminino (Online), v. 25, p. 236-246.

ONU. 1988. Conjunto de Princípios para a Proteção de Todas as Pessoas Sujeitas a Qualquer Forma de Detenção ou Prisão.

PASTORAL CARCERÁRIA. 2007. Relatório sobre mulheres encarceradas no Brasil.

\section{AUTORA:}

\section{Laura Monteiro Lubanco}

Mestra pelo Programa de Pós Graduação em Sociologia Política da Universidade Estadual do Norte Fluminense Darcy Ribeiro (UENF). 